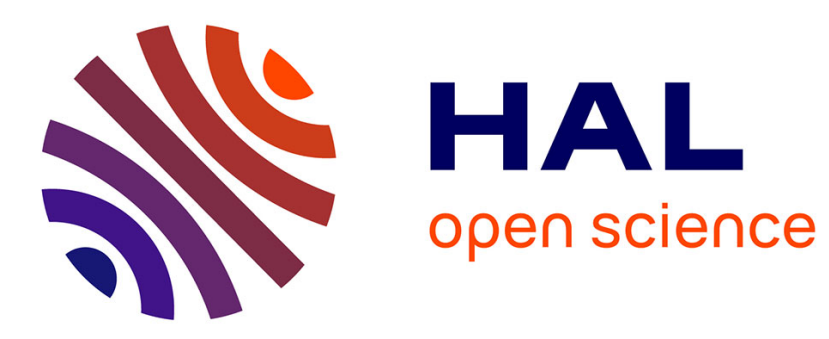

\title{
Stability of nanostructured silver-platinum alloys
}

\author{
Joanna Wisniewska, Hazar Guesmi, Maria Ziolek, Frederik Tielens
}

\section{To cite this version:}

Joanna Wisniewska, Hazar Guesmi, Maria Ziolek, Frederik Tielens. Stability of nanostructured silver-platinum alloys. Journal of Alloys and Compounds, 2018, 770, pp.934-941. 10.1016/j.jallcom.2018.08.208 . hal-01864134

\section{HAL Id: hal-01864134 \\ https://hal.science/hal-01864134}

Submitted on 2 Jan 2021

HAL is a multi-disciplinary open access archive for the deposit and dissemination of scientific research documents, whether they are published or not. The documents may come from teaching and research institutions in France or abroad, or from public or private research centers.
L'archive ouverte pluridisciplinaire HAL, est destinée au dépôt et à la diffusion de documents scientifiques de niveau recherche, publiés ou non, émanant des établissements d'enseignement et de recherche français ou étrangers, des laboratoires publics ou privés. 


\title{
Stability of nanostructured silver-platinum alloys
}

\author{
Joanna Wisniewska $^{\mathrm{a}, \mathrm{b}^{*}}$, Hazar Guesmi ${ }^{\mathrm{c}}$, Maria Ziolek ${ }^{\mathrm{a}}$, Frederik Tielens ${ }^{\mathrm{b}^{* *}}$
}

a Adam Mickiewicz University in Poznań, Faculty of Chemistry, Umultowska 89b, 61-614 Poznań, Poland

${ }^{\mathrm{b}}$ Vrije Universiteit Brussel (Free University Brussels-VUB), General Chemistry (ALGC), Pleinlaan 2, 1050 Brussel, Belgium.

${ }^{\mathrm{c}}$ Institut Charles Gerhardt Montpellier, CNRS/ENSCM/UM, 240, Avenue du Professeur Emile Jeanbrau, 34090 Montpellier, France

Corresponding authors :

*jc62431@amu.edu.pl

** frederik.tielens@,vub.be

\begin{abstract}
The stability of Ag-Pt systems: 13-atoms icosahedral cluster model $\left(\mathrm{Ag}_{13-\mathrm{n}} \mathrm{Pt}_{\mathrm{n}}\right)$ and 54-atoms (111) surface slab model (45Ag9Pt) have been systematically investigated by using Density Functional Theory within the generalized gradient approximation (DFT-GGA). Experimentally tested resistance of AgPt alloy nanoparticles supported on silica to decay upon temperature treatment ( $423 \mathrm{~K}-573 \mathrm{~K}$ in $\mathrm{N}_{2}$ flow) have shown to correlate with theoretical results. The stability of the clusters as a function of AgPt composition decreases with increasing content of Pt. The general stability trend of the AgPt alloy was maintained, in theory and experiment, for the Ag/Pt molar ratio of 1.6 - 5.1. Two particularly stable Ag/Pt compositions were revealed: 1.6 and 0.4 . It was also found that surface location of platinum is responsible for stabilization of the Ag-Pt nanostructured alloy.
\end{abstract}


Keywords: silver; platinum; stability; DFT, XRD, UV-Vis

\section{Introduction}

In materials science, the range of properties of metallic systems can be much extended by taking mixtures of elements to generate intermetallic compounds and alloys. Nanoalloys have become of particular interest mainly because they may display properties which are distinct from those of the pure clusters. Their chemical and physical properties may be tuned by varying the composition and atomic ordering as well as the size of the clusters [1,2]. In many cases, specific properties are enhanced upon alloying due to synergistic effect, which has led to widespread applications of alloys in optoelectronics [3,4], medicine and catalysis [2,5-8]. It is also worth noting that the properties of nanoalloys may be different from those of the ideal bulk because of the surface segregation and nanoscale effect $[1,9,10]$. The efficient development of bimetallic systems requires collaboration between theoretical modeling, experimental preparation and characterization techniques. It is still a challenge to obtain the atomic-scale structural and compositional information about nanoalloys at the experimental level. Furthermore, it is wellknown that the surface structure and atomic arrangement of experimentally prepared nanoalloys are influenced by many factors, e.g. the particle size, morphology and composition. This has become less problematic thanks to application of powerful theoretical methods $[9,11,12]$.

From among all bimetallic systems, platinum- based nanoalloys ( $\mathrm{Pt}-\mathrm{Cu}[5,13-15]$, PtCo[2,15,16], Pt-Fe[7,15,17], Pt-Ni[15], Pt-Pd[18,19], Pt-Rh[16], Pt-Au[16,20], Pt-Ru[21]) have been widely studied to reduce the amount of expensive Pt in technological applications. Although, numerous theoretical and experimental studies have been focused on the Ag-Pt nanosystem [9,22-29], still the controlled synthesis of AgPt alloy, the composition and structure dependence of its properties and stability need further exploration. Therefore, AgPt nanoalloy is an interesting system to investigate, especially considering the potential 
applications given the lower price of $\mathrm{Ag}$ and the limited resources of Pt. An additional inspiration for studying the stability of Ag-Pt bimetallic nanoparticles is motivated by the results obtained in our previous paper [30]. Indeed, it has been shown that bimetallic catalysts with Ag and Pt supported on silica (commercial and ordered mesoporous cellular foam - MCF) after calcination (the last step of preparation route) display Ag-Pt alloy-like particles. On the basis of these experimental results it has been postulated that the condition for alloy formation is the minimal $\mathrm{Ag} / \mathrm{Pt}$ molar ratio equal to 2.5 . On the majority of samples the alloy disappeared upon heating at $673 \mathrm{~K}$ for 2 hours in argon or hydrogen flow. Only bigger alloy particles remained after activation in inert gas. In the present study heating in $\mathrm{N}_{2}$ flow was applied, but at different temperatures $(423 \mathrm{~K}, 473 \mathrm{~K}, 523 \mathrm{~K}$ and $573 \mathrm{~K})$. For such a study amorphous silica or MCF were modified by silver and platinum species with $\mathrm{Ag} / \mathrm{Pt}$ molar ratio in range 0.4 to 5.1. The goal of this work was to find the optimal composition of Ag-Pt bimetallic nanoalloy which will display the highest stability according to DFT study and to check experimentally Ag-Pt alloy resistance to decay upon temperature treatment.

\section{Computational details}

\subsection{Methodology}

The geometry optimization, the calculation of the total energy were performed using PerdewBurke-Ernzerhof form of the spin-polarized generalized gradient approximation (GGAPBE)[31][32] functional, implemented in the Vienna Ab Initio Simulation Package (VASP) [33][34]. The valence electrons are treated explicitly, and their interactions with the ionic cores are described by the projector augmented-wave method (PAW)[35], which allows the use of a low-energy cutoff equal to $400 \mathrm{eV}$ for the plane-wave basis. To get the lowest energy of clusters each starting configuration was placed inside a large cubic box of $30 \times 30 \times 30 \AA$ and ensured that image interaction between clusters of two nearest boxes is negligible. For the slab models, $3 \times 3$ atoms were considered in one layer and similar six layers were taken in the Z-direction. 
For optimization of this slab, while atomic positions of top four layers were relaxed, atoms at 2 bottom layer were kept fixed at bulk values. The molecules are at large enough distance from each other, in order to avoid intermolecular interactions. The sampling in the Brillouin zone was performed employing k-points at a distance of each other of $30 \AA^{-1}$ in the reciprocal space.

\subsection{Description of models}

The aim of the theoretical study was to investigate the stability of two kinds of Ag-Pt systems:

a. 13-atoms cluster model: $\mathrm{Ag}_{13}, \mathrm{Pt}_{13}, \mathrm{Ag}_{13-\mathrm{n}} \mathrm{Pt}_{\mathrm{n}}$ (Fig. 1A)

b. 54-atoms (6-layers) (111) surface slab model: 45Ag9Pt, $\operatorname{Ag}(111), \operatorname{Pt}(111)$ (Fig. 1B)

Cluster models differ in the content of silver and platinum atoms and their positions. Slab models display constant composition (45 atoms of $\mathrm{Ag}$ and 9 atoms of $\mathrm{Pt}$ ) and differ just in the location of Pt atoms. Studied slab models (Fig. 1B) consist of 6 layers in which the top four layers were allowed to relax, whereas the two bottom layers were fixed at their crystallographic bulk positions. To analyze the stability of $\mathrm{Ag}_{13-\mathrm{n}} \mathrm{Pt}_{\mathrm{n}}$ clusters and $45 \mathrm{Ag} 9 \mathrm{Pt}$ slab models, the excess energy per atom $\left(\Delta \mathrm{E}_{\mathrm{exc}}\right)$ was calculated [11]. The $\Delta \mathrm{E}_{\mathrm{exc}}$ measure the stability of the studied systems with respect to the parent compounds. It is defined by the following equation:

$\Delta E_{e x c}=\frac{E^{A g_{13-n} P t_{n}}-\frac{n}{13} E^{P t_{13}}-\frac{13-n}{13} E^{A g_{13}}}{13} \quad$ for the cluster model

$\Delta E_{\text {exc }}=\frac{E^{45 A g 9 P t}-\frac{9}{54} E^{P t(111)}-\frac{45}{54} E^{A g(111)}}{54} \quad$ for the slab model,

with:

$\Delta E_{\text {exc }}-$ the excess energy per atom,

$E^{A g_{13-n} P t_{n}}, E^{45 A g 9 P t}-$ total energy of the bimetallic model,

$E^{P t_{13}}, E^{P t(111)}-$ total energy of $\mathrm{Pt}_{13}$ or bulk Pt(111) model, 
$E^{A g_{13}}, E^{A g(111)}$ - total energy of $\operatorname{Ag}_{13}$ or bulk $\mathrm{Ag}(111)$ model.

For pure metals $\left(\mathrm{Ag}_{13}, \mathrm{Pt}_{13}\right.$, bulk $\operatorname{Ag}(111)$, bulk $\left.\mathrm{Pt}(111)\right) \Delta E_{\text {exc }}$ is set to be $0.00 \mathrm{eV}$. A negative value of excess energy indicates a tendency to form nanoalloys (the mixing is energetically favorable), and the lower the value of excess energy, the higher the stability of the structure [15]. Additionally, segregation energy was calculated for selected clusters and slab models. The segregation energy $\left(E_{\text {seg }}\right)$ of $\mathrm{Pt}$ atoms in silver slab was defined by equation (3).

$$
E_{\text {seg. }}=\left[E_{\text {AgPt(Pt } x \text {-layer })}-E_{\text {AgPt(Pt } 4 \text { th-layer })}\right] / N_{P t}
$$

where $E_{\mathrm{AgPt}(\mathrm{Pt} \text { x-layer) }}$ represents the total energy of the AgPt alloy system (the slab of 54 atoms) with Pt layer located in the upper $\mathrm{x}$ layers of $\mathrm{Ag} \operatorname{slab}(\mathrm{x}=1,2$ or 3$)$, and $E_{\text {AgPt(Pt } 4 \text { th-layer })}$ represents the total energy of the AgPt alloy system with the Pt located in the $4^{\text {th }}$ Ag layer slab, which corresponds to the presence of Pt atoms in the "bulk" silver. For cluster model this energy is calculated as the difference between cluster with the central $\mathrm{Pt}$ ( $\mathrm{Pt}$ in the bulk) and corresponding structure with Pt segregated to the surface.

\section{Experimental}

\subsection{Preparation of catalysts}

Amorphous silica (Ultrasil) or mesoporous MCF were grafted with 3mercaptopropyltrimethoxysilane (MPTMS) (95\%, Sigma-Aldrich) to functionalize its surface before modification with metals. To obtain bimetallic (Ag-Pt) catalysts the same procedure as in our previous work [36] was used (S1- SD). The Ag/Pt molar ratios: 0.4, 1.6, 2.5, 3.6 and 5.1 $\mathrm{Ag} / \mathrm{Pt}$ were applied. The total amount of metals did not exceed 3 wt. \%. After metals loading, the samples were calcined in air at $773 \mathrm{~K}$ for $4 \mathrm{~h}$. The actual approximate $\mathrm{Ag} / \mathrm{Pt}$ molar ratio is indicated in the material symbol, e.g. $0.4 \mathrm{AgPt} / \mathrm{SiO}_{2}$ means $\mathrm{Ag} / \mathrm{Pt}$ molar ratio equal to 0.4.

\subsection{Test of stability upon temperature treatment}


The stability of AgPt alloy particles was tested by heating the prepared samples at different temperatures $(423 \mathrm{~K}, 473 \mathrm{~K}, 523 \mathrm{~K}$ and $573 \mathrm{~K})$ in $\mathrm{N}_{2}$ flow $(40 \mathrm{~mL} / \mathrm{min})$ for 2 hours. Directly after cooling down the samples were analyzed with the use of UV-Vis spectroscopy and X-Ray Diffraction.

X-Ray Diffraction. XRD measurements were carried out on a Bruker AXS D8Advance diffractometer with $\mathrm{Cu} \mathrm{Ka}$ radiation $(\mathrm{k}=0.154 \mathrm{~nm})$, with a step size of $0.05^{\circ}$ in the wide-angle range $6^{\circ}-60^{\circ}$

UV-Vis spectroscopy. UV-Vis spectra were recorded using a Varian-Cary 300 Scan UVVisible spectrophotometer. Powder samples, directly after heating and cooling down were placed in a cell equipped with a quartz window. The spectra were recorded in the range from 800 to $190 \mathrm{~nm}$. Spectralon was used as the reference material.

\section{Results and discussion}

\subsection{Theoretical results}

\subsubsection{The cluster model}

Literature data [37][38] suggest that a stable series of cluster catalysts should have the topological magic number structure (e.g., $\left.\mathrm{Pt}_{13}, \mathrm{Pt}_{55}, \ldots\right)$ with high symmetry. $\mathrm{The} \mathrm{Pt}_{13}$ has a well-known icosahedral atomic coordination as part of the stable cluster series. Therefore, the $\mathrm{Pt}_{13}$ cluster as the initial structure was chosen to construct the alloy cluster. Different metals $\mathrm{Ag} / \mathrm{Pt}$ ratios in the range 0.1 to 12.0 were applied.

Systematic study of 75 configurations of $\mathrm{Ag}_{13-\mathrm{n}} \mathrm{Pt}_{\mathrm{n}}$ alloy cluster was performed, (Fig. S1-SD). The most stable structures are presented in Fig. 2. Calculated total energies, excess energies and segregation energies per atom are collected in Table S1-SD. As presented in Fig. 3. the formation of the alloy-like $\mathrm{Ag}_{13-\mathrm{n}} \mathrm{Pt}_{\mathrm{n}}$ nanoclusters is energetically favorable for almost all compositions as the excess energy is negative in most cases. The exceptions are clusters with $\mathrm{Ag} / \mathrm{Pt}$ molar ratio in the low range $(0.1-0.3)$ with $\mathrm{Ag}$ atom located at the center. Taking into 
account the most stable clusters from each group with the same composition, the excess energy $\Delta E_{\text {exc }}$ decreases (indicating the increasing stability of alloy) by replacing $\mathrm{Ag}$ atoms by $\mathrm{Pt}$ atoms in the cluster, and it reaches a minimum at $\mathrm{n}=5(\mathrm{Ag} / \mathrm{Pt}$ molar ratio $=1.6)$. Then, the excess energy per atom increases (indicating a decrease in stability of the nanocluster) and reaches 0.0 $\mathrm{eV}$ at $\mathrm{n}=13\left(\mathrm{Pt}_{13}\right)$. A similar tendency for Pt-containing bimetallic clusters has been reported in literature for $\mathrm{Pt}_{\mathrm{n}} \mathrm{TM}_{55-\mathrm{n}}(\mathrm{TM}=\mathrm{Fe}, \mathrm{Co}, \mathrm{Ni}, \mathrm{Cu}$, and $\mathrm{Zn})[15]$ and $\mathrm{Pt}_{\mathrm{n}} \mathrm{TM}_{55-\mathrm{n}}(\mathrm{TM}=\mathrm{Co}, \mathrm{Rh}$, $\mathrm{Au}$ ) [16] systems. The most stable nanoclusters were characterized by the silver to platinum molar ratio of $0.4-2.4$ (4-9 $\mathrm{Pt}$ atoms in $\mathrm{Ag}_{13-\mathrm{n}} \mathrm{Pt}_{\mathrm{n}}$ clusters). It was also noticed that the central site is preferably occupied by $\mathrm{Pt}$ atom in the energetically favorable $\mathrm{Ag}_{13-\mathrm{n}} \mathrm{Pt}_{\mathrm{n}}$ nanoparticles, regardless of the $\mathrm{Ag} / \mathrm{Pt}$ molar ratio (Fig. 2.). It indicates that the $\mathrm{Pt}$ atom in the central site is responsible for strong stabilization of icosahedral structures. This is due to the strong cohesive energy of $\mathrm{Pt}(5.84 \mathrm{eV})$ compared to $\mathrm{Ag}(2.95 \mathrm{eV})$ as well as the lower surface energy of $\mathrm{Ag}$ compared to Pt. A similar bulk segregation phenomenon, with the Pt atoms at the cluster core has been observed for Pt-Pd nanoclusters [39]. In the Fig. 4., the evolution of surface segregation energy of Pt in AgPt clusters (from the central position to the surface) with the increasing $\mathrm{Ag} / \mathrm{Pt}$ molar ratio has been plotted. Interestingly, the segregation of $\mathrm{Pt}$ is found to depends on Pt loading. For clusters with Ag/Pt molar ratio lower than 0.4 and higher than 2.0, the location of Pt on the surface is found to be highly unfavourable. Such alloy clusters display lower stability than clusters with Ag/Pt molar ratio in the range of $1.6-0.4$ with preferable surface location of platinum. This conclusion is in line with the experimental results, showed in the later section.

As presented in Fig. 5, the Ag-Pt distances $(2.80 \AA, 2.77 \AA)$ in the bimetallic cluster are shorter in comparison with the Ag-Ag ones $(2.92 \AA ; 2.78 \AA)$ in the silver cluster and longer in comparison with Pt-Pt $(2.75 \AA ; 2.62 \AA)$ in the platinum cluster, located at the similar positions. 
This indicates that the icosahedron structure is slightly distorted. Thus, different interactions between monometallic and bimetallic clusters with different reagents can be expected.

\subsubsection{The slab model}

The slab models considered are shown in Fig. 6. The (111) surface of Pt and Ag are thermodynamically the most stable so they were used as references. The goal was to determine the effect of platinum location on the stability of bimetallic AgPt in slab models. Six slab models were studied, with different Pt atom positions: (a) platinum on the top, (b) Pt in the $2^{\text {nd }}$ layer, (c) Pt in the $3^{\text {rd }}$ layer, (d) Pt in the $4^{\text {th }}$ layer (e) Pt atoms agglomerates (f) bimetallic surface. As seen in Table S2-SD, the values of all calculated excess energies are close to $0 \mathrm{eV} /$ atom, i.e within the precision of the calculation level. Thus, only general tendency of changes, not the actual values of excess energies can be considered. From the energy segregation of a layer of Pt in Ag structure and the effect of order (Table S2-SD) it can be seen the segregation tendency. Surface location of $\mathrm{Ag}$ atoms is energetically favored (45Ag9Pt $3^{\text {rd }}$ and $45 \mathrm{Ag} 9 \mathrm{Pt} \_4^{\text {th }}$ models) which is in agreement with the Monte Carlo studies performed on Ag-Pt system [9]. The data presented indicate the limitation in construction of $\mathrm{AgPt}$ alloy structures, such as their size. The slab models which describe the surface of bigger bimetallic particles are much less stable than the cluster models describing particles with sizes less than $10 \mathrm{~nm}$. These differences are caused by limited miscibility between $\mathrm{Ag}$ and $\mathrm{Pt}$ in bulk materials. Narrowing or complete disappearance of miscibility gaps for nanostructured platinum alloys is fundamentally interesting, and potentially very useful for controlling the properties that cannot be achieved through bulk alloys [10][40][41]. When the particle size is reduced to nanoscale, often the change in phase behavior is observed and the phase diagram based on bulk bimetallic systems cannot be simply applied for nanoalloys [1][10][40].

\subsection{Experimental results}


Fundamental characterization of catalysts calcined at $773 \mathrm{~K}$ in air has been presented in our previous paper[30]. After calcination, $\mathrm{Ag}$ and $\mathrm{Pt}$ are mainly in the form of $\mathrm{Ag}-\mathrm{Pt}$ alloy nanoparticles. On the basis of TEM images particle size distribution was estimated and particles in the range of 4-6 $\mathrm{nm}$ were found to dominate. It means that the $\mathrm{Ag}_{13-\mathrm{n}} \mathrm{Pt}_{\mathrm{n}}$ cluster model is better equivalent of the actual AgPt alloy particles in prepared catalysts than semi-infinite surface presented by slab models. In Fig. $7 \mathrm{Ag} / \mathrm{Pt}$ molar ratios are shown corresponding to real values studied in the experimental part.

XRD patterns (Fig. 8) of calcined samples with $\mathrm{Ag} / \mathrm{Pt}$ ratio equal to 2.5, 3.6, 5.1 show reflections at $2 \theta \approx 31.8^{\circ}, 32.9^{\circ}, 33.9^{\circ}$ from silver oxide planes [42]; $2 \theta \approx 39.8^{\circ}, 46.2^{\circ}$ from metallic $\mathrm{Pt}^{0}[43][44]$; and $2 \theta \approx 37.9^{\circ}, 41.0^{\circ}, 46.7^{\circ}$ from Ag-Pt alloy particles [30]. For the sample with the highest amount of $\mathrm{Pt}(\mathrm{Ag} / \mathrm{Pt}=0.4)$ there are only reflections from metallic platinum, however it does not exclude the presence of very small alloy particles (below the limits of X-Ray Diffraction detection). The reflections from alloy are not observed neither in the XRD pattern of the sample with $\mathrm{Ag} / \mathrm{Pt}=1.6$, although the metallic platinum and silver oxide are well distinguished. Types of active species in calcined samples were also estimated from UV-Vis spectra (Fig. 9). According to literature a surface plasmon resonance band of spherical metallic silver nanoparticles appears at $400 \mathrm{~nm}$ [45], whereas the band at $267 \mathrm{~nm}$ can be assigned to metallic platinum [46] or cationic silver species [47]. Blue shift of UV-Vis band coming from metallic silver from $400 \mathrm{~nm}$ to lower wavelengths $(300-400 \mathrm{~nm}$ range) is caused by the formation of alloy Ag-Pt structure. The band at a lower than $400 \mathrm{~nm}$ wavelength originates from d-d electron transfer in alloy Ag-Pt particles [30][48]. Thus, the presence of AgPt alloy particles in all calcined samples is confirmed by UV-Vis spectra shown in Fig. 9. XRD patterns of samples heated at $423 \mathrm{~K}$ under $\mathrm{N}_{2}$ flow permit differentiating between the stability of alloy particles in the studied samples. Reflections from alloy disappear for 5.1 $\mathrm{AgPt} / \mathrm{SiO}_{2}$, whereas in the other samples they remain (Fig. 8.). For the samples with higher 
amount of $\mathrm{Pt}$ (lower $\mathrm{Ag} / \mathrm{Pt}$ molar ratio) analogous changes (disappearance of alloy reflections) but at higher temperatures: $473 \mathrm{~K}$ for $3.6 \mathrm{AgPt} / \mathrm{SiO}_{2}$ and $523 \mathrm{~K}$ for $2.5 \mathrm{AgPt} / \mathrm{SiO}_{2}$ are observed. On the basis of XRD patterns it is not possible to conclude about stability of AgPt alloy in samples: $0.4 \mathrm{AgPt} / \mathrm{SiO}_{2}$ and $1.6 \mathrm{AgPt} / \mathrm{MCF}$ because the peaks from alloy were not visible in the parent, calcined materials. Therefore, the stability of alloy for these samples was studied by $\mathrm{UV}$-Vis spectroscopy. In the $\mathrm{UV}-\mathrm{V}$ is spectra of both samples $(\mathrm{Ag} / \mathrm{Pt}=0.4$ and 1.6) after heating at $473 \mathrm{~K}$ and $523 \mathrm{~K}$, a low-intense broad band with a maximum between $300-500 \mathrm{~nm}$ is still visible, indicating the presence of alloy particles. Additional study of the 1.6AgPt/MCF sample heated at a higher temperature $(573 \mathrm{~K})$ showed that the UV-Vis band assigned to Ag-Pt alloy is still present in the spectrum. Slight separation of bands indicates just partial alloy decompsition. The experimental results are in agreement with the theoretical calculations performed for $\mathrm{Ag}_{13-\mathrm{n}} \mathrm{Pt}_{\mathrm{n}}$ cluster model, the stability of $\mathrm{AgPt}$ alloy nanoparticles strongly depends on the metals content. The stability of the nanoalloy increases in the following sequence: $5.1<$ $3.6<2.5<1.6$ of Ag/Pt molar ratio. Thus, the conclusion from our previous work, which says that the necessary condition for the formation of $\mathrm{AgPt}$ nanoalloy is the presence of high excess of silver in relation to $\mathrm{Pt}$, should be verified on the basis of the results presented here. The $\mathrm{AgPt}$ alloy nanoparticles can be formed in a broad range of $\mathrm{Ag} / \mathrm{Pt}$ molar ratios, but the composition and size of the alloy particles strongly determines the temperature stability of the alloy structure.

\section{CONCLUSIONS}

DFT calculations were performed to study the stability of Ag-Pt 13-atom icosahedral clusters and of slabs. For all $\mathrm{Ag}_{13-\mathrm{n}} \mathrm{Pt}_{\mathrm{n}}$ clusters, the formation of icosahedron configurations with $\mathrm{Pt}$ atom at the center is energetically favorable. The stability behavior of the theoretical AgPt cluster models is in agreement with experiment. The stability of the clusters as a function of $\mathrm{Ag} / \mathrm{Pt}$ composition decreases with increasing content of Pt. The general stability trend was maintained for the $\mathrm{Ag} / \mathrm{Pt}$ molar ratio of $0.4-5.1$. Two particularly stable compositions were revealed as 
those with $\mathrm{Ag} / \mathrm{Pt}$ ratios of 1.6 and 0.4 . According to the results $45 \mathrm{Ag} 9 \mathrm{Pt}$ slab models, which corresponds to bulk alloys, are much less. The reason for that is the miscibility gap between bulk silver and platinum. Thus, Ag-Pt alloy can be formed in a broad range of Ag/Pt ratio, but its stability depends on the metals content and size of the bimetallic particles. The knowledge about the dimension and composition of the most temperature stable Ag-Pt alloys is of a great interest for users in many disciplines.

\section{Supporting Information}

S1 - Synthesis procedure

Figure S1. - Studied configurations of the bimetallic $\operatorname{Ag}_{13-n} \mathrm{Pt}_{\mathrm{n}}(\mathrm{n}=1-12)$ nanoclusters.

Table S1. - The calculated total energies, excess energies per atom and segregation energies for $\mathrm{Ag}_{13-\mathrm{n}} \mathrm{Pt}_{\mathrm{n}}$ cluster models.

Table S2. - The calculated total energies, excess energies per atom and segregation energies for 45Ag9Pt slab models.

\section{AUTHOR INFORMATION}

*Corresponding author:

Joanna Wisniewska, E-mail: jc62431@amu.edu.pl

Adam Mickiewicz University in Poznań, Faculty of Chemistry, Umultowska 89b, 61-614 Poznań, Poland

Telephone: +48618291794

\section{ACKNOWLEDGEMENTS}


J. Wisniewska would like to thank Dr. Jan Turek from Vrije Universiteit Brussel (Free University Brussels-VUB) for patiently answering all questions about VASP calculations, many useful advices and his selfless generosity not only in science field.

Computational resources and services were provided by the Shared ICT Services Centre funded by the Vrije Universiteit Brussel, the Flemish Supercomputer Center (VSC) and FWO.

National Science Centre in Poland (Grant No. 2015/19/N/ST5/00501) is acknowledged for the financial support of this work.

\section{REFERENCES}

[1] R. Ferrando, J. Jellinek, R.L. Johnston, Nanoalloys : From Theory to Applications of Alloy Clusters and Nanoparticles, Chem. Rev. 108 (2008) 845-910.

[2] S. Zafeiratos, S. Piccinin, D. Teschner, Alloys in catalysis: phase separation and surface segregation phenomena in response to the reactive environment, Catal. Sci. Technol. 2 (2012) 1787-1801.

[3] J. Gao, X. Ren, D. Chen, F. Tang, J. Ren, Bimetallic Ag-Pt hollow nanoparticles: Synthesis and tunable surface plasmon resonance, Scr. Mater. 57 (2007) 687-690.

[4] E. Aldirmaz, M. Guler, E. Guler, A. Dere, A. Tataroğlu, A.G. Al-sehemi, A.A. Alghamdi, F. Yakuphanoglu, A shape memory alloy based on photodiode for optoelectronic applications, J. Alloys Compd. 743 (2018) 227-233.

[5] W. Zhang, Q. Dong, H. Lu, B. Hu, Y. Xie, G. Yu, Glucose-directed synthesis of Pt-Cu alloy nanowires networks and their electro- catalytic performance for ethylene glycol oxidation, J. Alloys Compd. 727 (2017) 475-483. 
[6] M.A. Gondal, A.A. Adeseda, S.G. Rashid, A. Hameed, M. Aslam, I.M.I. Ismail, U. Baig, M.A. Dastageer, A.R. Al-Arfaj, A.U. Rehman, Facile synthesis, characterization and photocatalytic performance of Au-Ag alloy nanoparticles dispersed on graphitic carbon nitride under visible light irradiations, J. Mol. Catal. A Chem. 423 (2016) 114-125.

[7] N. Wang, Y. Li, Z. Guo, H. Li, S. Hayase, T. Ma, Minute quantities of hexagonal nanoplates PtFe alloy with facile operating conditions enhanced electrocatalytic activity and durability for oxygen reduction reaction, J. Alloys Compd. 752 (2018) 23-31.

[8] M. Du, B. Chen, Y. Hu, J. Chen, J. Nie, G. Ma, Pt-based alloy nanoparticles embedded electrospun porous carbon nanofibers as electrocatalysts for Methanol oxidation reaction, J. Alloys Compd. 747 (2018) 978-988.

[9] L. Deng, H. Deng, S. Xiao, J. Tang, W. Hu, Morphology, dimension, and composition dependence of thermodynamically preferred atomic arrangements in Ag-Pt nanoalloys, Faraday Discuss. 162 (2013) 293-306.

[10] Z. Peng, H. Yang, Designer platinum nanoparticles: Control of shape, composition in alloy, nanostructure and electrocatalytic property, Nano Today. 4 (2009) 143-164.

[11] M. Dhifallah, A. Dhouib, S. Aldulaijan, F.D.I. Renzo, H. Guesmi, M. Dhifallah, A. Dhouib, S. Aldulaijan, F.D.I. Renzo, First-principles study of $\mathrm{Au}-\mathrm{Cu}$ alloy surface changes induced by gas adsorption of $\mathrm{CO}$, NO or $\mathrm{O}_{2}$, J. Chem. Phys. 145 (2016) 1-8.

[12] H. Guesmi, Theoretical insights on the effect of reactive gas on the chemical ordering of gold-based alloys, Gold Bull. (2013) 213-219.

[13] X. Lei, H. Mu, S. Li, G. Liu, B. Xu, C. Ouyang, H. Mu, S. Li, G. Liu, B. Xu, C. Ouyang, The structural and electronic properties of Pt-Cu alloy clusters: Embedding atom method combined with density functional theory study, J. Alloys Compd. 741 (2018) 604-609. 
[14] S. Zhou, B. Varughese, B. Eichhorn, G. Jackson, K. Mcilwrath, Pt-Cu Core-Shell and Alloy Nanoparticles for Heterogeneous NO, Angew. Chemie - Int. Ed. 44 (2005) 45394543.

[15] D. Guedes-Sobrinho, R.K. Nomiyama, A.S. Chaves, J. Piotrowski, J.L.F. Da Silva, Structure, Electronic, and Magnetic Properties of Binary Pt n TM $55-\mathrm{n}(\mathrm{TM}=\mathrm{Fe}$, $\mathrm{Co}, \mathrm{Ni}, \mathrm{Cu}, \mathrm{Zn}$ ) Nanoclusters : A Density Functional Theory Investigation, J. Phys. Chem. C. 119 (2015) 15669-15679.

[16] M.J. Piotrowski, P. Piquini, J.L.F. Da Silva, Platinum-based nanoalloys $\mathrm{Pt}_{\mathrm{n}} \mathrm{TM}_{55-\mathrm{n}}$ (TM $=\mathrm{Co}, \mathrm{Rh}, \mathrm{Au}):$ A density functional theory investigation, J. Phys. Chem. C. 116 (2012) 18432-18439.

[17] Y. Zhou, C. Zhu, G. Yang, D. Du, X. Cheng, J. Yang, Y. Lin, Embedding platinumbased nanoparticles within ordered mesoporous carbon using supercritical carbon dioxide technique as a highly ef fi cient oxygen reduction electrocatalyst, J. Alloys Compd. 741 (2018) 580-589.

[18] E. Sosa, H. Liu, Oxygen adsorption on Pt-Pd nanoclusters by DFT and ab initio atomistic thermodynamics, J. Alloys Compd. 735 (2017) 643-653.

[19] S. Li, Y. Yang, S. Huang, Theoretical insights into the relationship between structures and properties in tri-metallic $\mathrm{Pd}_{13-n} \mathrm{Ni}_{\mathrm{n}} @ \mathrm{Pt}_{42}(\mathrm{n}=0-13)$ nanoparticles, Comput. Theor. Chem. 1107 (2017) 94-101.

[20] C. Song, Q. Ge, L. Wang, DFT studies of Pt/Au bimetallic clusters and their interactions with the CO molecule, J. Phys. Chem. B. 109 (2005) 22341-22350.

[21] L. Semiz, N. Abdullayeva, M. Sankir, Nanoporous Pt and Ru catalysts by chemical dealloying of Pt-Al and Ru-Al alloys for ultrafast hydrogen generation, J. Alloys Compd. 
744 (2018) 110-115.

[22] M.T. Schaal, M.P. Hyman, M. Rangan, S. Ma, C.T. Williams, J.R. Monnier, J.W. Medlin, Theoretical and experimental studies of Ag-Pt interactions for supported Ag-Pt bimetallic catalysts, Surf. Sci. 603 (2009) 690-696.

[23] L. Feng, G. Gao, P. Huang, X. Wang, C. Zhang, J. Zhang, S. Guo, D. Cui, Preparation of Pt Ag alloy nanoisland/graphene hybrid composites and its high stability and catalytic activity in methanol electro-oxidation, Nanoscale Res. Lett. 6 (2011) 551-561.

[24] G.L.W. Hart, L.J. Nelson, R.R. Van, B.J. Campbell, M.H.F. Sluiter, J.H. Neethling, E.J. Olivier, S. Allies, C.I. Lang, B. Meredig, C. Wolverton, Acta Materialia Revisiting the revised Ag-Pt phase diagram, Acta Mater. 124 (2017) 325-332.

[25] A. Bin Yousaf, M. Imran, A. Zeb, T. Wen, X. Xie, Y.F. Jiang, C.Z. Yuan, A.W. Xu, Single Phase PtAg Bimetallic Alloy Nanoparticles Highly Dispersed on Reduced Graphene Oxide for Electrocatalytic Application of Methanol Oxidation Reaction, Electrochim. Acta. 197 (2016) 117-125.

[26] W. He, X. Wu, J. Liu, K. Zhang, W. Chu, L. Feng, X. Hu, W. Zhou, S. Xie, Formation of AgPt alloy nanoislands via chemical etching with tunable optical and catalytic properties, Langmuir. 26 (2010) 4443-4448.

[27] S.Y. Hwang, C. Zhang, E. Yurchekfrodl, Z. Peng, Property of Pt - Ag Alloy Nanoparticle Catalysts in Carbon Monoxide Oxidation, J. Phys. Chem. C. (2014) 2873928745.

[28] Z. Peng, H. You, H. Yang, An electrochemical approach to PtAg alloy nanostructures rich in Pt at the surface, Adv. Funct. Mater. 20 (2010) 3734-3741. 
[29] K. Li, F. He, G. Xie, Y. Wang, M. Jiao, H. Tang, Z. Wu, The Influence of Pt Layers in $\mathrm{Ag} @ \mathrm{Pt}_{\mathrm{n}} \mathrm{L}(111$ ) ( $\mathrm{n}=1$ and 2 ) on Oxygen Reduction Reaction : A Theoretical Study, J. Electrochem. Soc. 163 (2016) 945-951.

[30] J. Wisniewska, M. Ziolek, Formation of Pt-Ag alloy on different silicas - surface properties and catalytic activity in oxidation of methanol, RSC Adv. 7 (2017) 95349544.

[31] J.P. Perdew, K. Burke, M. Ernzerhof, Generalized Gradient Approximation Made Simple, Phys. Rev. Lett. 18 (1996) 3865-3868.

[32] J.P. Perdew, K. Burke, M. Ernzerhof, Perdew, Burke, and Ernzhof Reply, Phys. Rev. Lett. 80 (4) (1998) 891.

[33] G. Kresse, J. Hafner, Ab initio molecular dynamics for open-shell transition metals, Phys. Rev. B. 48 (1993) 48-51.

[34] G. Kresse, J. Hafner, Ab initio molecular-dynamics liquid-metal — amorphoussemiconductor simulation of the transition in germanium., Phys. Rev. B. 49 (1994) $14251-14269$.

[35] P. Blochl, Projector augmented-wave method, Phys. Rev. B. 50 (1994) 17953-17979.

[36] J. Wisniewska, M. Ziolek, N. Artioli, M. Daturi, The effect of niobium and tantalum on physicochemical and catalytic properties of silver and platinum catalysts based on MCF mesoporous cellular foams, J. Catal. 336 (2016) 58-75.

[37] T. Imaoka, H. Kitazawa, W.J. Chun, S. Omura, K. Albrecht, K. Yamamoto, Magic number $\mathrm{Pt}_{13}$ and misshapen $\mathrm{Pt}_{12}$ clusters: Which one is the better catalyst?, J. Am. Chem. Soc. 135 (2013) 13089-13095. 
[38] Y. Chi, L. Zhao, X. Lu, C. An, W. Guo, C.M.L. Wu, Effect of alloying on the catalytic properties of Pt-Ni bimetallic subnanoclusters: a theoretical investigation, J. Mater. Sci. 51 (2016) 5046-5060.

[39] A. Radillo-Díaz, Y. Coronado, L.A. Pérez, I.L. Garzón, Structural and electronic properties of PtPd and PtNi nanoalloys, Eur. Phys. J. D. 52 (2009) 127-130.

[40] Z. Peng, H. Yang, Ag-Pt alloy nanoparticles with the compositions in the miscibility gap, J. Solid State Chem. 181 (2008) 1546-1551.

[41] W. He, X. Wu, J. Liu, X. Hu, K. Zhang, S. Hou, W. Zhou, S. Xie, Design of AgM bimetallic alloy nanostructures $(\mathrm{M}=\mathrm{Au}, \mathrm{Pd}, \mathrm{Pt})$ with tunable morphology and peroxidase-like activity, Chem. Mater. 22 (2010) 2988-2994.

[42] G. Valverde-Aguilar, J. García-Macedo, V. Rentería-Tapia, Silver Core - Silver Oxide Shell Nanoparticles Embedded on Mesostructured Silica Films, J. Nano Res. 3 (2008) $103-114$.

[43] X. Chen, J. Chen, Y. Zhao, M. Chen, H. Wan, Effect of dispersion on catalytic performance of supported pt catalysts for co oxidation, Chinese J. Catal. 33 (2012) 19011905.

[44] I. Sobczak, J. Grams, M. Ziolek, Surface properties of platinum catalysts based on various nanoporous matrices, Microporous Mesoporous Mater. 99 (2007) 345-354.

[45] L. Suber, I. Sondi, E. Matijević, D. V. Goia, Preparation and the mechanisms of formation of silver particles of different morphologies in homogeneous solutions, J. Colloid Interface Sci. 288 (2005) 489-495.

[46] E. Gharibshahi, E. Saion, Influence of dose on particle size and optical properties of 
colloidal platinum nanoparticles, Int. J. Mol. Sci. 13 (2012) 14723-14741.

[47] P.M. More, D.L. Nguyen, M.K. Dongare, S.B. Umbarkar, N. Nuns, J.S. Girardon, C. Dujardin, C. Lancelot, A.S. Mamede, P. Granger, Rational preparation of Ag and Au bimetallic catalysts for the hydrocarbon-SCR of $\mathrm{NO}_{\mathrm{x}}$ : Sequential deposition vs. coprecipitation method, Appl. Catal. B Environ. 162 (2015) 11-20.

[48] X. Liu, A. Wang, X. Yang, T. Zhang, C. Mou, Synthesis of Thermally Stable and Highly Active Bimetallic Au - Ag Nanoparticles on Inert Supports, (2009) 410-418. 


\section{FIGURES CAPTIONS}

Figure 1. Studied models: 13-atoms $\mathrm{Ag}_{13-\mathrm{n}} \mathrm{Pt}_{\mathrm{n}}$ cluster (A) and 54-atoms 45Ag9Pt slab (B)

Figure 2. The most stable structures of $\mathrm{Ag}_{13-\mathrm{n}} \mathrm{Pt}_{\mathrm{n}}$ clusters ( $\left.\mathrm{n}=1-12\right) ; \mathrm{Ag}$ - orange, $\mathrm{Pt}$ - green.

Figure 3. Calculated $\Delta \mathrm{E}_{\mathrm{exc}}\left(\mathrm{eV} /\right.$ atom) $\mathrm{Ag}_{13-\mathrm{n}} \mathrm{Pt}_{\mathrm{n}}$ as a function of the composition (number of $\mathrm{Pt}$ atoms and $\mathrm{Ag} / \mathrm{Pt}$ molar ratio). The continuous line connects the excess energies with the lowest energy configurations.

Figure 4. Relationship between $\mathrm{Ag} / \mathrm{Pt}$ molar ratio and calculated segregation energy (eV/atom) of platinum in cluster models.

Figure 5. The comparison of Ag-Pt, Ag-Ag and Pt-Pt bond lengths in monometallic and bimetallic clusters; Ag - orange, Pt- green.

Figure 6. Studied 6-layers (111) surface slab models: 45Ag9Pt ( $\mathrm{Ag} / \mathrm{Pt}=5.0), \mathrm{Ag}(111), \mathrm{Pt}(111)$; $\mathrm{Ag}$ - orange, Pt- green.

Figure 7. Relationship between temperature stability of AgPt alloy and its composition theoretical and experimental results.

Figure 8. XRD patterns of bimetallic Ag-Pt samples: calcined and after heating in $\mathrm{N}_{2}$ flow at $423 \mathrm{~K}, 473 \mathrm{~K}, 523 \mathrm{~K}$ and $573 \mathrm{~K}(40 \mathrm{~mL} / \mathrm{min})$ for 2 hours.

Figure 9. UV-Vis spectra of bimetallic Ag-Pt samples: fresh and after heating in $\mathrm{N}_{2}$ flow at 423 $\mathrm{K}, 473 \mathrm{~K}, 523 \mathrm{~K}, 573 \mathrm{~K}(40 \mathrm{~mL} / \mathrm{min})$ for 2 hours. 
A

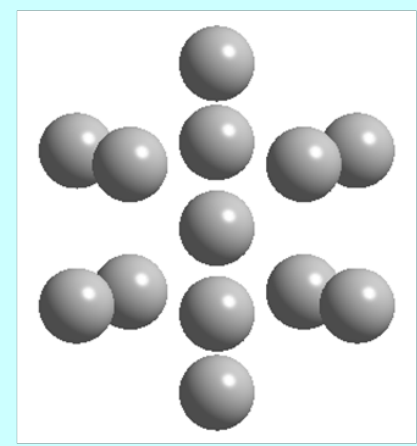

13-atoms cluster model
B

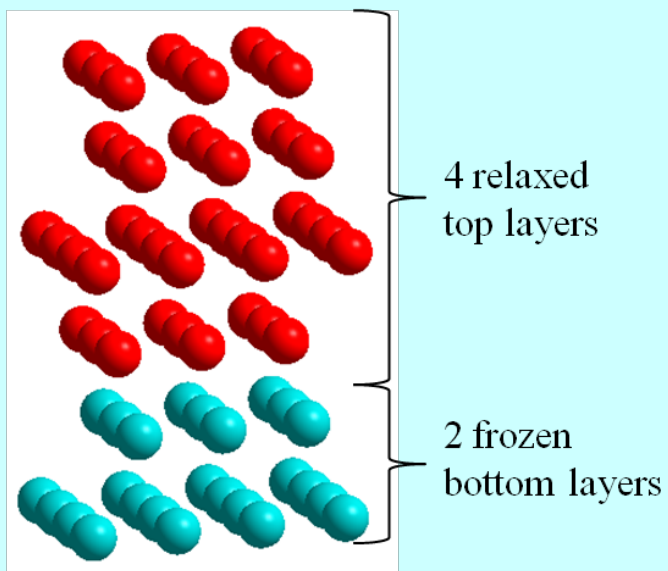

54-atoms slab model

Figure 1. Studied models: 13 -atoms $\mathrm{Ag}_{13-\mathrm{n}} \mathrm{Pt}_{\mathrm{n}}$ cluster (A) and 54-atoms $45 \mathrm{Ag} 9 \mathrm{Pt}$ slab (B). All bonds between the atoms are not shown for reasons of clarity. 

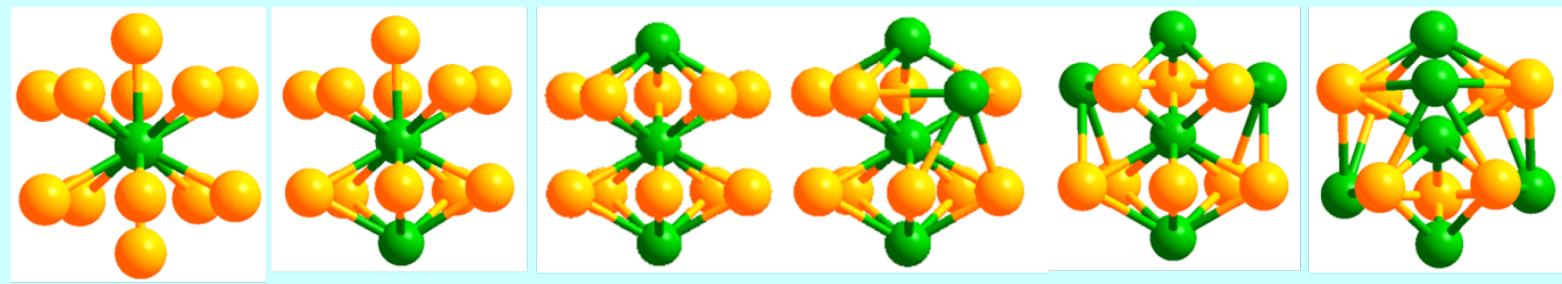

$\mathrm{Ag}_{12} \mathrm{Pt}_{1 \_} 1$

$\mathrm{Ag}_{11} \mathrm{Pt}_{2 \_} 1$

$\mathrm{Ag}_{10} \mathrm{Pt}_{3} 1$

$\mathrm{Ag}_{9} \mathrm{Pt}_{4-1} \mathrm{l}$

$\mathrm{Ag}_{8} \mathrm{Pt}_{5} 3$

$\mathrm{Ag}_{7} \mathrm{Pt}_{6} 4$

$\Delta \mathrm{E}_{\mathrm{exc}}=-0.10 \mathrm{eV}$

$\Delta \mathrm{E}_{\mathrm{exc}}=-0.13 \mathrm{eV}$

$\Delta \mathrm{E}_{\mathrm{exc}}=-0.18 \mathrm{eV}$

$\Delta \mathrm{E}_{\mathrm{exc}}=-0.20 \mathrm{eV}$

$\Delta \mathrm{E}_{\mathrm{exc}}=-0.22 \mathrm{eV}$

$\Delta \mathrm{E}_{\mathrm{exc}}=-0.20 \mathrm{eV}$

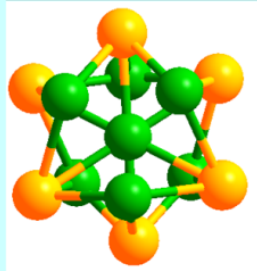

$\mathrm{Ag}_{6} \mathrm{Pt}_{7} 7$ $\Delta \mathrm{E}_{\mathrm{exc}}=-0.19 \mathrm{eV}$

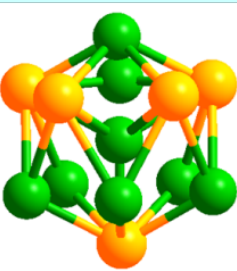

$\mathrm{Ag}_{5} \mathrm{Pt}_{8_{-}} 5$ $\Delta \mathrm{E}_{\mathrm{exc}}=-0.19 \mathrm{eV}$

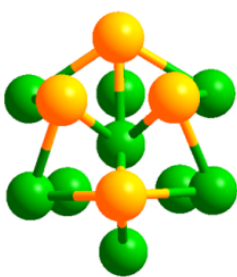

$\mathrm{Ag}_{4} \mathrm{Pt}_{9-6} 6$ $\Delta \mathrm{E}_{\mathrm{exc}}=-0.19 \mathrm{eV}$

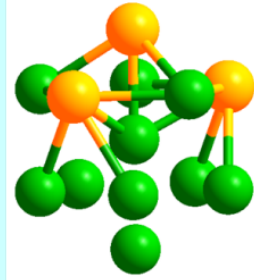

$\mathrm{Ag}_{3} \mathrm{Pt}_{10} 4$ $\Delta \mathrm{E}_{\mathrm{exc}}=-0.17 \mathrm{eV}$

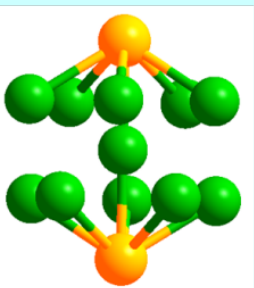

$\mathrm{Ag}_{2} \mathrm{Pt}_{11}{ }_{2}$

$\Delta \mathrm{E}_{\mathrm{exc}}=-0.09 \mathrm{eV}$

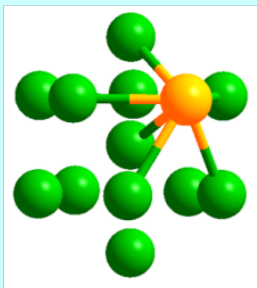

$\mathrm{Ag}_{1} \mathrm{Pt}_{12} 2$

$\Delta \mathrm{E}_{\mathrm{exc}}=-0.03 \mathrm{eV}$

Figure 2. The most stable structures of $\mathrm{Ag}_{13-\mathrm{n}} \mathrm{Pt}_{\mathrm{n}}$ clusters ( $\left.\mathrm{n}=1-12\right) ; \mathrm{Ag}$ - orange, $\mathrm{Pt}$ - green.

All bonds between the atoms are not shown for reasons of clarity. 

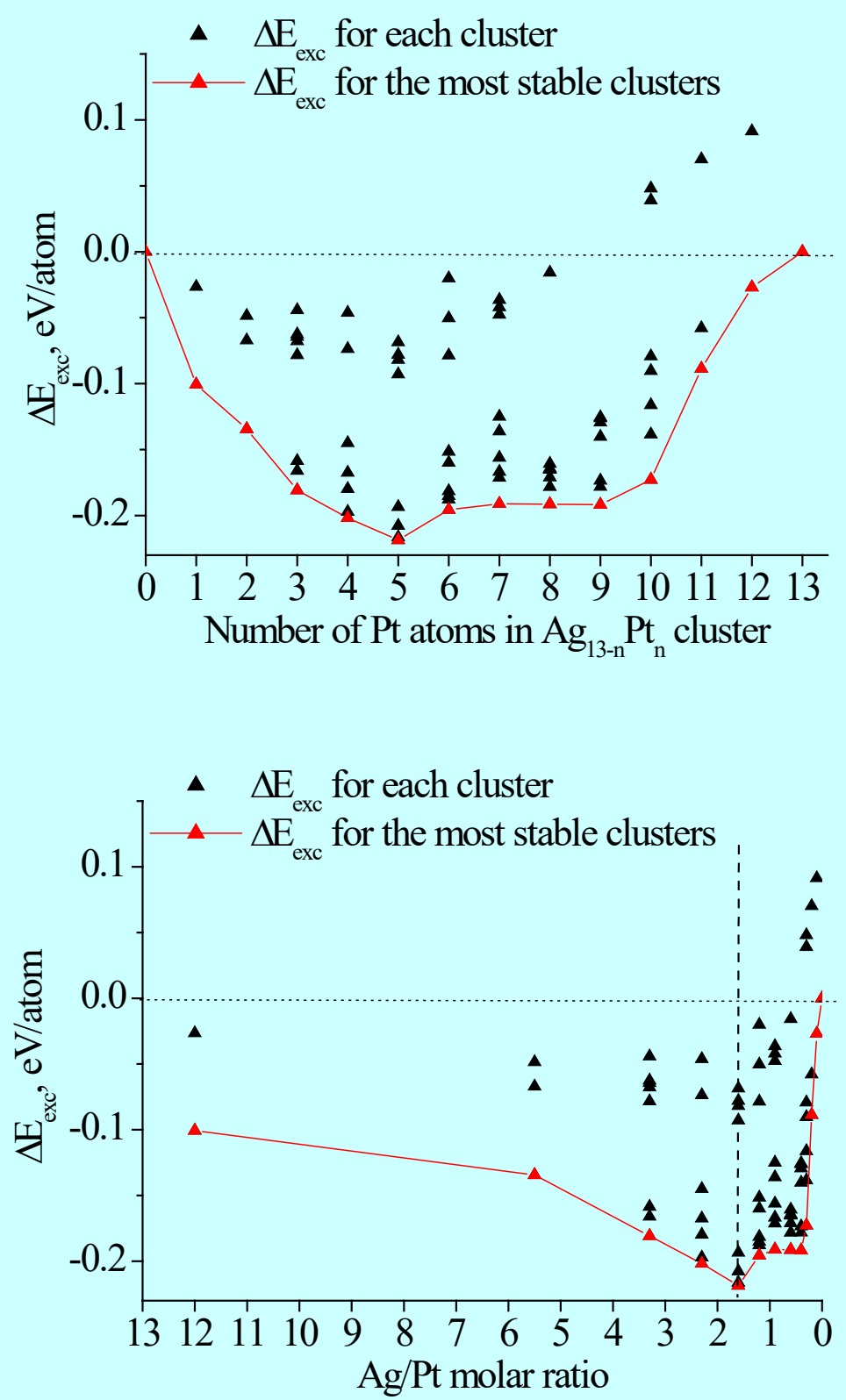

Figure 3. Calculated $\Delta \mathrm{E}_{\mathrm{exc}}\left(\mathrm{eV} /\right.$ atom) $\mathrm{Ag}_{13-\mathrm{n}} \mathrm{Pt}_{\mathrm{n}}$ as a function of the composition (number of $\mathrm{Pt}$ atoms and $\mathrm{Ag} / \mathrm{Pt}$ molar ratio). The continuous line connects the excess energies with the lowest energy configurations. 


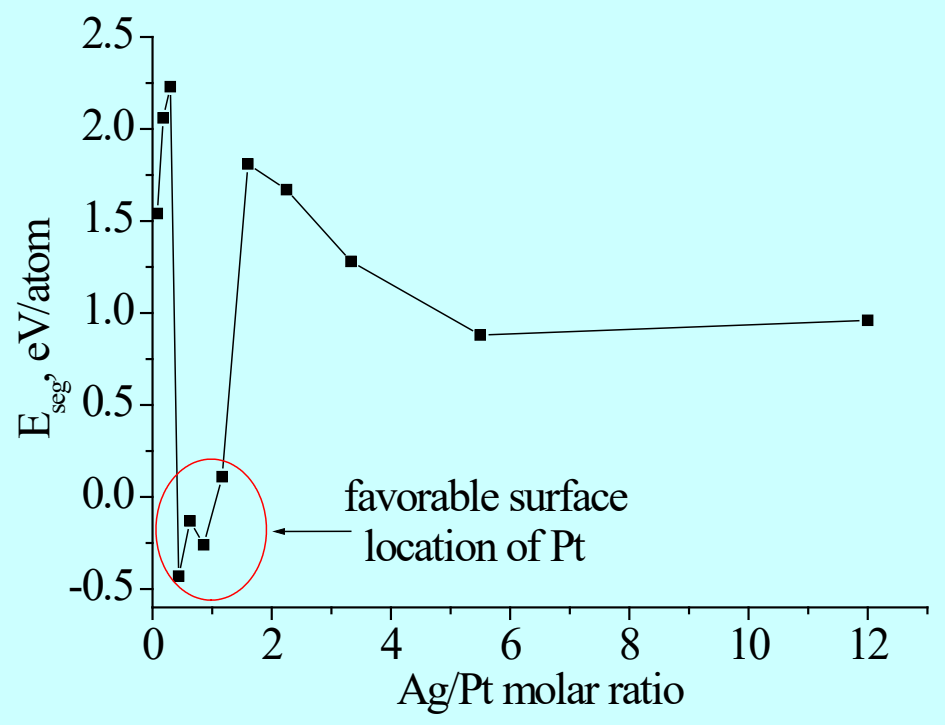

Figure 4. Relationship between Ag/Pt molar ratio and calculated segregation energy (eV/atom) of platinum in cluster models. 


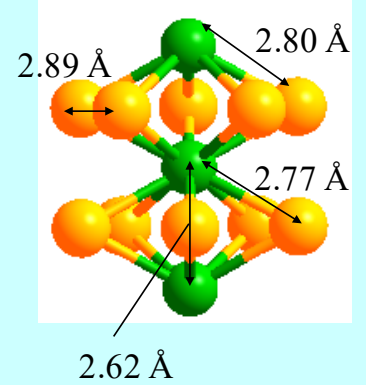

$\mathrm{Ag}_{10} \mathrm{Pt}_{3-} 1$

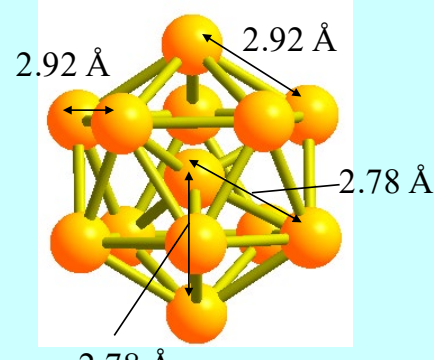

$2.78 \AA$

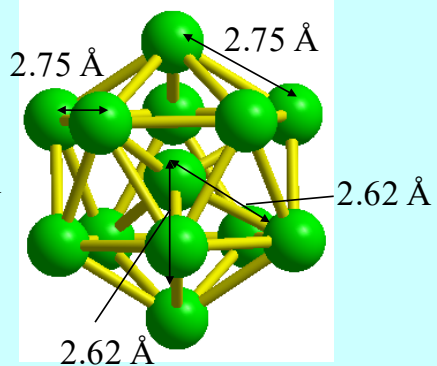

$\mathrm{Pt}_{13}$

Figure 5. The comparison of Ag-Pt, Ag-Ag and Pt-Pt bond lengths in monometallic and bimetallic clusters; Ag - orange, Pt- green. 
a)

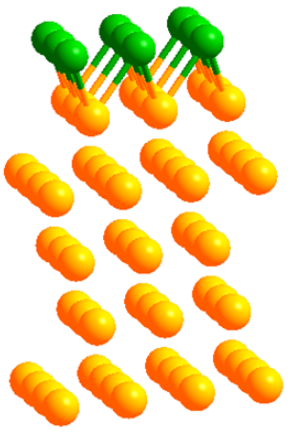

45Ag9Pt_top

d)

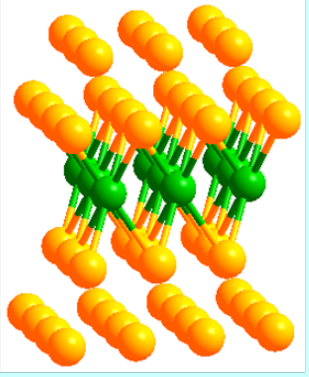

45Ag9Pt_4 $4^{\text {th }}$ layer

g)

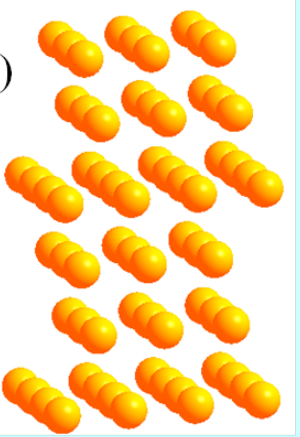

$\operatorname{Ag}(111)$ b)

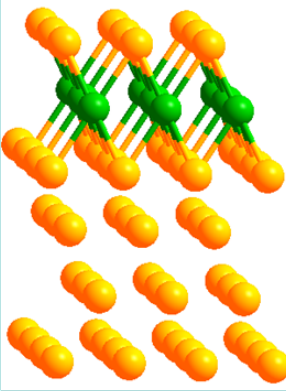

45Ag9Pt_2ndlayer

e)

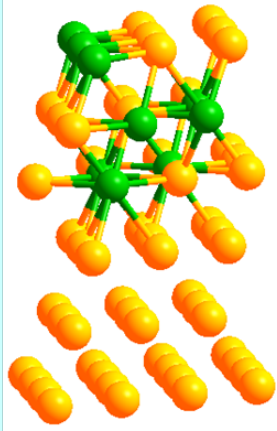

45Ag9Pt_agglomerate

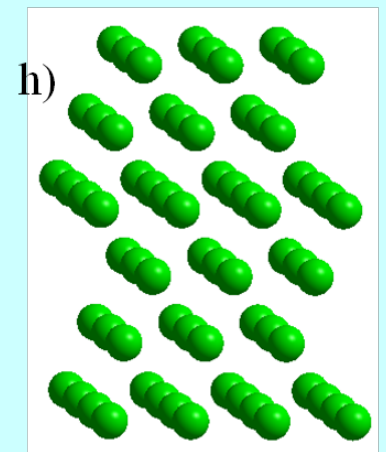

$\operatorname{Pt}(111)$ c) 900

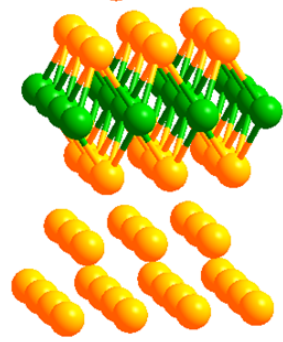

45Ag9Pt_3 ${ }^{\text {rd layer }}$

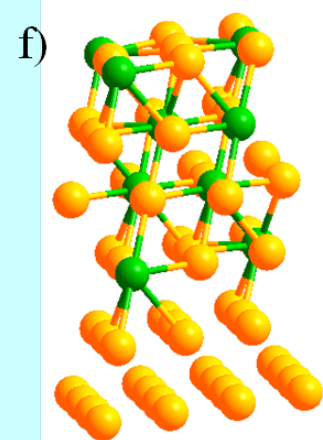

45Ag9Pt_bimetallic surface

Pt(111)

Figure 6. 6-layers (111) surface slab models: 45Ag9Pt (Ag/Pt =5.0), $\mathrm{Ag}(111), \mathrm{Pt}(111), \mathrm{Ag}$ - orange, Pt- green. All bonds between the atoms are not shown for reasons of clarity. 


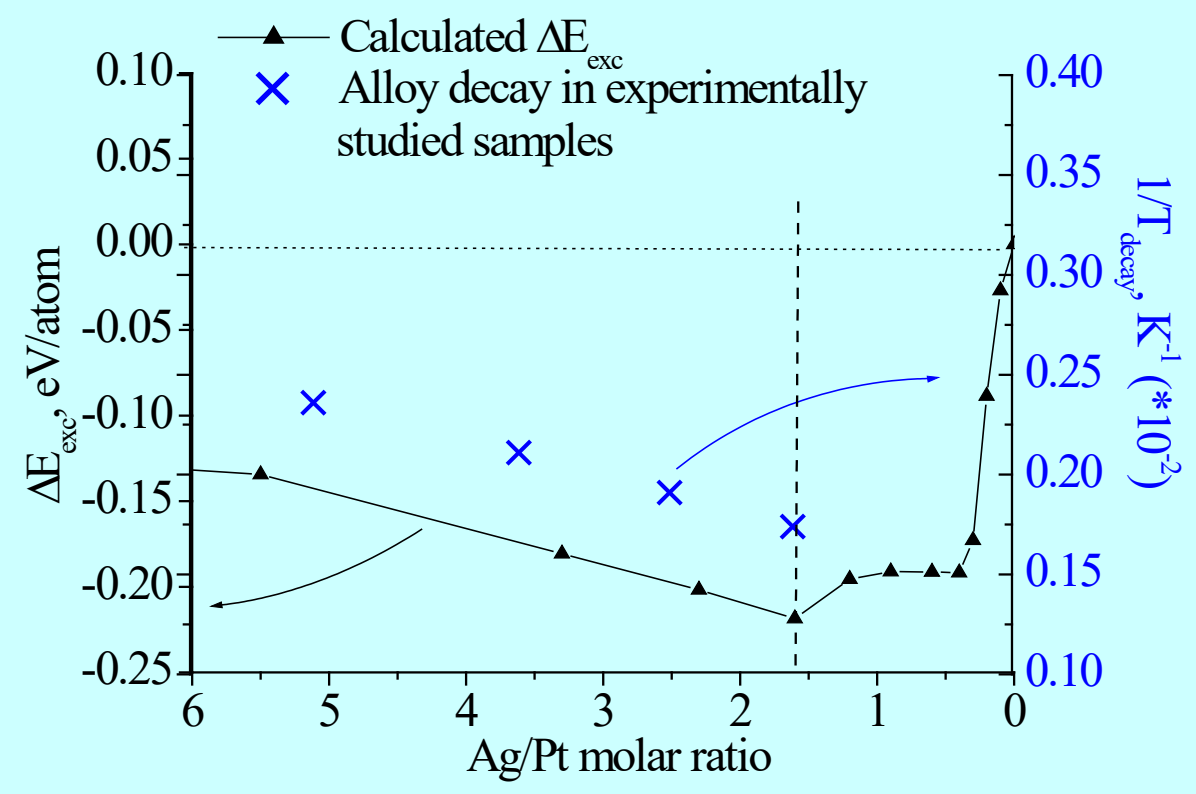

Figure 7. Relationship between temperature stability of AgPt alloy and its composition theoretical and experimental results. 

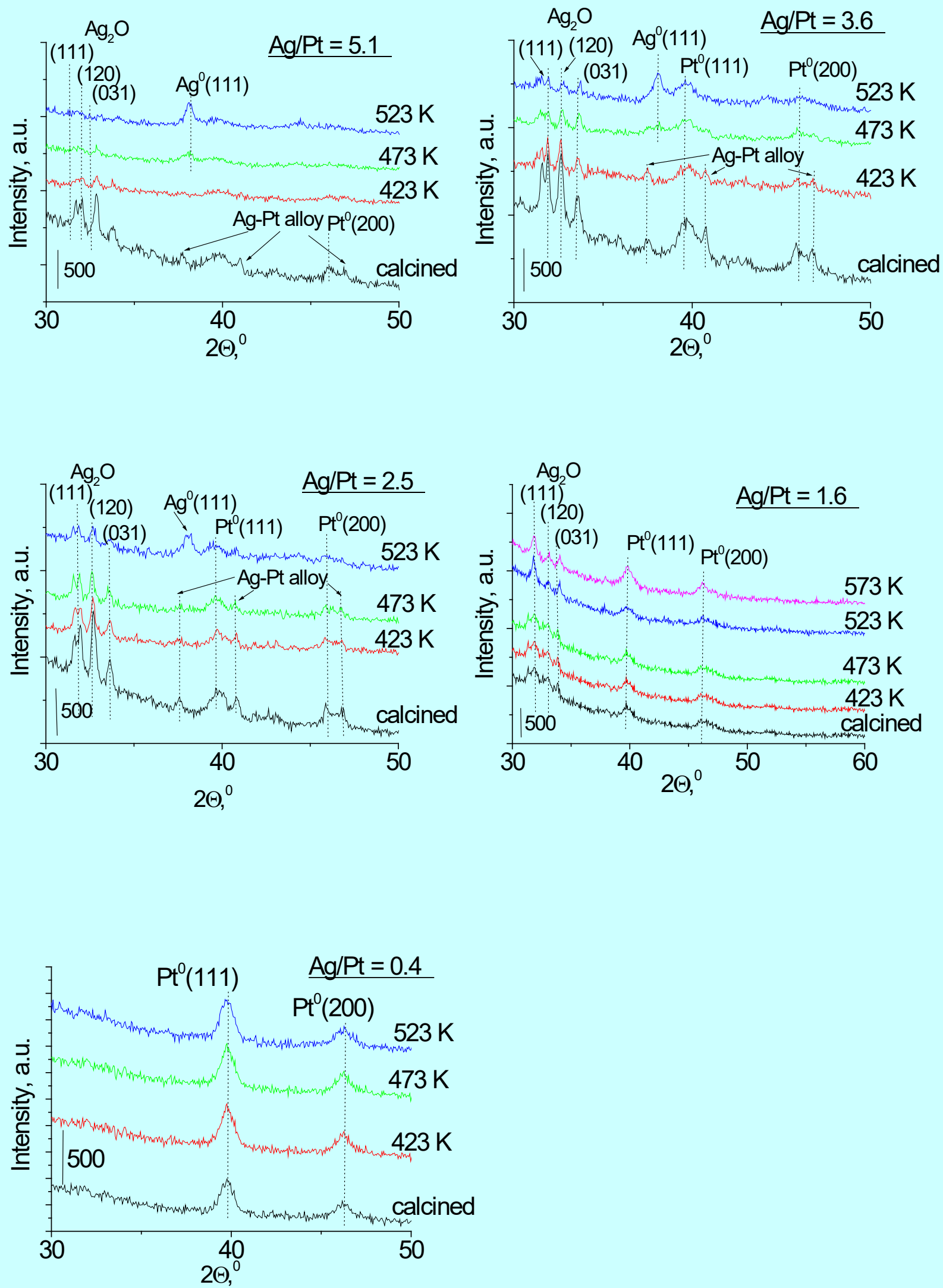

Figure 8. XRD patterns of bimetallic Ag-Pt samples: calcined samples and after heating at $423 \mathrm{~K}, 473 \mathrm{~K}, 523 \mathrm{~K}$ and $573 \mathrm{~K}$ in $\mathrm{N}_{2}$ flow $(40 \mathrm{~mL} / \mathrm{min})$ for 2 hours. 

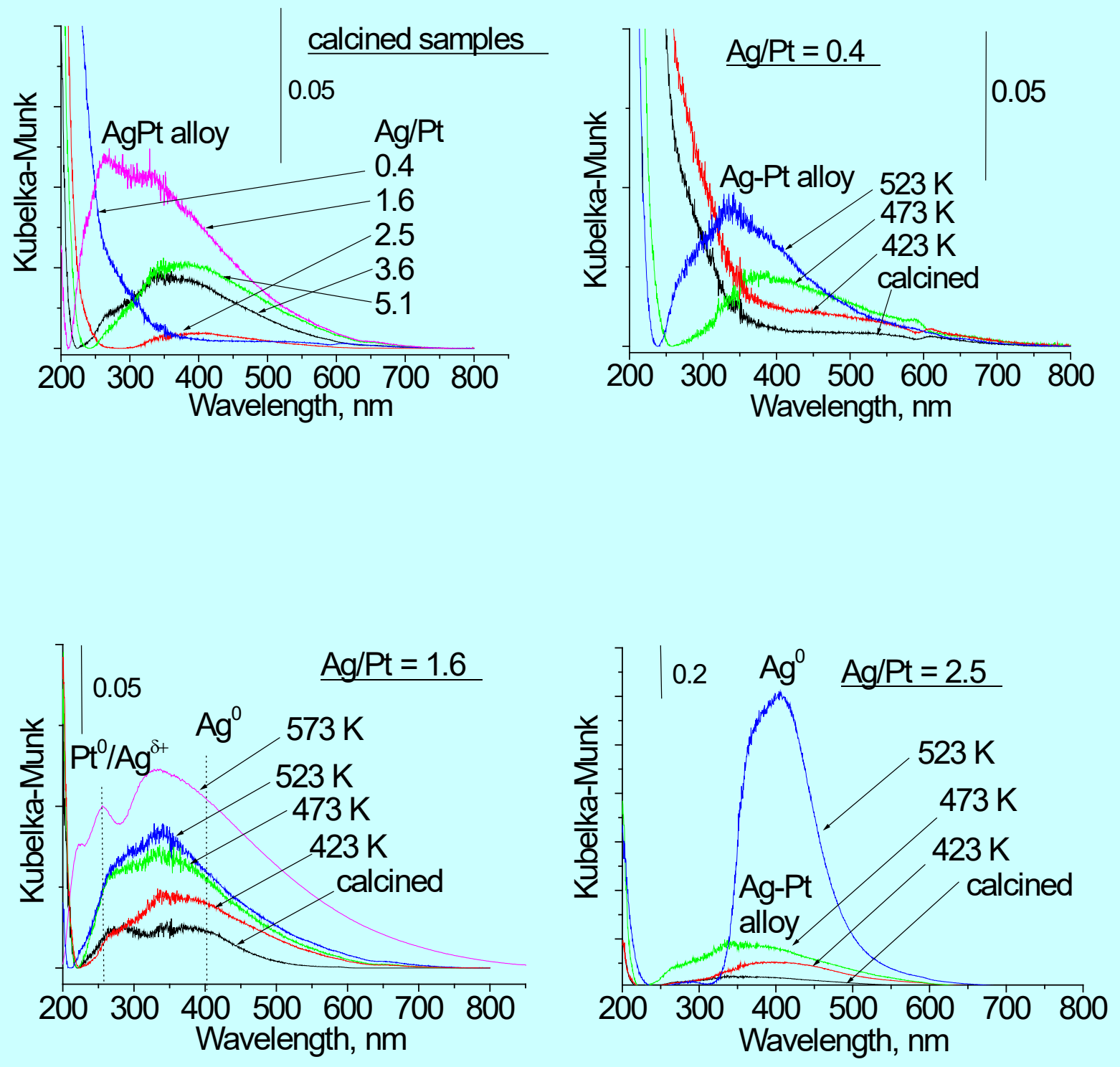

Figure 9. UV-Vis spectra of bimetallic Ag-Pt samples: calcined samples and after heating at $423 \mathrm{~K}, 473 \mathrm{~K}, 523 \mathrm{~K}$ and $573 \mathrm{~K}$ in $\mathrm{N}_{2}$ flow ( $40 \mathrm{~mL} / \mathrm{min}$ ) for 2 hours. 